\title{
Labyrinthe
}

$40 \mid 2013$

Comme les abeilles

\section{Le mythe de la bougonie : Aristée, Orphée, Virgile}

\section{Renaud Pasquier}

\section{(2) OpenEdition}

\section{Journals}

Édition électronique

URL : http://journals.openedition.org/labyrinthe/4331

DOI : $10.4000 /$ labyrinthe.4331

ISSN : 1950-6031

Éditeur

Hermann

Édition imprimée

Date de publication : 1 mars 2013

Pagination : 135-139

ISBN : 9782705688400

\section{Référence électronique}

Renaud Pasquier, «Le mythe de la bougonie : Aristée, Orphée, Virgile », Labyrinthe [En ligne], 40 | 2013,

mis en ligne le 01 mars 2015, consulté le 30 avril 2019. URL : http://journals.openedition.org/

labyrinthe/4331 ; DOI : 10.4000/labyrinthe.4331 


\section{Le mythe de la bougonie: Aristée, Orphée, Virgile}

Renaud PASQUIER

Peu à peu, tandis que Virgile achève la description ethnographique de la ruche, un glissement s'opère dans son propos: il célèbre d'abord la chasteté des abeilles, et le renouvellement de l'espèce par une miraculeuse génération spontanée; il explique ensuite leur admirable organisation sociale par un lien privilégié avec la divinité, puisque les abeilles posséderaient une «parcelle d'intelligence divine » (partem divinae mentis, vers 220); après ce bref aperçu d'une mystique panthéiste, il semble revenir aux conseils pratiques concernant la récolte du miel et surtout la reproduction des abeilles quand la ruche est dévastée et l'essaim décimé (où l'on retrouve les soucis macabres du début du poème) mais ce n'est que pour mieux décrire le sacrifice d'un taureau, dont renaîtraient les essaims, avant de raconter les origines de ce rituel, dans un mythe qui va occuper toute la fin du poème. Ainsi la tresse des savoirs agronomique, ethnologique et politique cède la place au discours religieux et mythologique.

Posons-le d'emblée, on tiendra que ce passage au mythe donne sens et unité aux différents discours qui trament le poème. Résumons d'abord le récit, ou plutôt les récits : le berger (et apiculteur) Aristée est donc désigné comme l'inventeur de cette méthode miraculeuse pour repeupler les ruches; retrouvant un jour les siennes désertes, il implora, désespéré, sa mère la déesse Cyrène. Celle-ci lui conseilla d'interroger Protée, le dieu très savant; ce dernier révèle à Aristée qu'il est coupable de la disparition de ses abeilles : s'il n'avait pas poursuivi la belle Eurydice de ses assiduités, elle n'aurait pas marché sur le serpent dont la morsure l'envoya aux Enfers. Protée abandonne alors un temps Aristée pour conter la triste histoire d'Orphée et Eurydice, enchâssée, donc, dans celle d'Aristée. Le récit achevé, Cyrène conseille à son fils de sacrifier quatre jeunes taureaux aux nymphes, amies d'Eurydice, irritées contre lui, et responsables de 


\section{Labyrinthe, $n^{\circ} 40$}

la disparition des abeilles. Le sacrifice est minutieusement décrit par Virgile, et les essaims apparaissent dans le sang du taureau.

Comment comprendre, d'abord, pourquoi Virgile conclut son traité d'agronomie par un mythe ? Est-ce seulement, comme ses lecteurs l'ont très souvent avancé, pour prendre congé du genre de la poésie géorgique, et annoncer son entrée en épopée ? Rien n'interdit de le penser, mais on ne se contentera pas de cette lecture. Comment, surtout, comprendre le mythe lui-même, où se rencontrent la mort, l'amour, la poésie, et les abeilles ? Il a suscité de très nombreuses interprétations, qu'on ne passera pas ici en revue. Rappelons seulement celle de Marcel Détienne, qui, dans son article « Orphée au miel ${ }^{1}$ » (texte méthodologique autant qu'analytique, où il érige ce récit en cas d'école pour l'analyse des mythes), s'attache à la représentation de la sexualité: Aristée serait puni pour ses excès (son désir effréné pour Eurydice), justement par la disparition des abeilles, symbole de virginité, et de vertu maritale; mais Orphée ne serait pas mieux loti, son amour pour Eurydice relevant d'une passion immodérée, et non du sage amour matrimonial. Aristée réussirait donc là où Orphée échouerait, en disciplinant et donc en civilisant ses sentiments et son comportement, ce que le retour des abeilles sanctifierait. Aristée incarnerait alors « une forme de vie cultivée », sociale et productive, dont l'apiculture serait l'activité emblématique.

Dans l'interprétation de Détienne - sommairement esquissée ici - et dans la plupart des autres, Orphée et Aristée sont mis en regard, toujours au détriment du premier. Virgile chanterait ainsi la déroute du poète et le triomphe de l'homme pratique, la victoire du producteur sur le rêveur. Aristée et Orphée sont tous deux confrontés à la mort, et sont prêts à tout pour renverser le cours des choses. Orphée perd Eurydice, et finit par mourir, tué par les nymphes irritées par son chagrin inconsolable et son incapacité à faire le deuil de sa bien-aimée; Aristée déjoue les ruses de Protée, manifeste sa piété filiale (en obéissant à sa mère) et religieuse (par le sacrifice des taureaux) et retrouve ses essaims. Virgile conclurait donc son œuvre sur un ton mélancolique, amer même, mais pleinement cohérent avec son projet: en célébrant la supériorité de l'agriculteur/berger/apiculteur, cheville ouvrière de l'économie et de la société romaines voulues par Auguste, et en peignant la faiblesse et

1. Marcel Détienne, « Orphée au miel », Quaderni urbinai di cultura classica, 12, 1971, p. 7-23. 


\section{Le mythe de la bougonie: Aristée, Orphée, Virgile}

l'impuissance du poète, maître de la beauté et de la séduction, certes, mais largement inutile dans le monde moderne.

Reste que cette supposée célébration d'Aristée emprunte les mots d'Orphée : ceux du mythe. Le poète dirait donc sa propre insignifiance, mais dans son langage spécifique: l'entrelacs de discours et de motifs autour des abeilles se complique à nouveau. Mieux encore, pourquoi achever un ouvrage didactique, à visée pratique, par un ultime conseil que rien ne justifie sinon un récit mythologique ? Virgile croyait-il vraiment en la « bougonie » (la naissance des abeilles dans les cadavres de taureaux) et en son origine mythique ? Était-elle aussi « vraie » pour lui que les savoirs techniques qu'il met en scène dans son poème? Il y a là une incohérence, ou du moins une étrangeté dans la structure et la logique même des Géorgiques.

Tenons alors qu'au contraire Virgile a voulu célébrer le poète et sa fonction dans un monde de préoccupations matérielles et pratiques. $\mathrm{Si}$ l'on regarde de plus près le « couple » Orphée/Aristée, où le second semblait au premier abord très supérieur au premier, on constate que les portraits dessinés par Virgile appellent au moins à la nuance: Aristée est un violeur (ici il en reste à l'intention, d'autres variantes du mythe sont plus explicites) qui jamais n'exprime le moindre remords pour son crime, uniquement préoccupé par la disparition de ses abeilles, qui n'a aucun mérite personnel à trouver une solution à ses problèmes, guidé d'abord par sa mère Cyrène, puis par Protée, et qui enfin accomplit un sacrifice des plus sanglants, dont Virgile ne nous épargne aucun détail, insistant sur sa cruauté extrême; Orphée, lui, est admiré de tous, la beauté de son chant est unanimement reconnue, l'univers entier partage sa tristesse, et il a vraiment réussi à revenir du royaume des morts (tandis que les abeilles d'Aristée ne ressuscitent pas, ce sont de nouveaux essaims qui naissent des taureaux). D'un côté (Aristée, mais aussi Auguste ?) la brutalité froide, de l'autre (Orphée, et à coup sûr Virgile) la beauté et le souci d'autrui, plantes, bêtes ou hommes. Ainsi le mythe conclusif des Géorgiques est-il bien « vrai », non au sens technique ou scientifique du terme, car l'on peut supposer à bon droit que jamais Virgile n'a réellement cru en la réalité concrète de la bougonie: il est vrai dans la mesure où il met en scène, en son langage, cette humanité supérieure du poète, et sa fragilité. Ce faisant, ce mythe complète aussi le manque de la première partie, où, on l'a relevé, la comparaison classique entre abeilles et poètes était absente: si elle n'est pas formulée non plus dans 


\section{Labyrinthe, $n^{\circ} 40$}

la deuxième, elle y est en revanche démontrée en acte. La fragilité des abeilles était omniprésente dans la première partie, celle du poète est évidente dans la deuxième. Surtout l'une et l'autre occupent des statuts d'intermédiaire: l'abeille circule entre végétaux et animaux, entre animaux et hommes, entre mortels et divinités, entre la vie et mort; le poète fait le lien entre homme et nature, hommes et dieux, mais aussi, on l'a vu, entre les savoirs. Le poète, sujet et objet de compassion (dans la figure d'Orphée), est inquiet, pour lui comme pour les autres, hommes et abeilles. Il est fragile, son art est fragile, comme l'est toute vie, comme le sont les abeilles. 
Well I'm a king bee

Buzzing around your hive Well I'm a king bee, baby Buzzing around your hive Yeah I can make honey baby Let me come inside

Muddy Waters 